\title{
Carbohydrate mouth rinsing has no effect on power output during cycling in a glycogen-reduced state
}

\author{
Ajmol Ali ${ }^{1 *}$, Michelle Ji Yeon Yoo ${ }^{2}$, Catherine Moss ${ }^{1}$ and Bernhard H. Breier ${ }^{3}$
}

\begin{abstract}
Background: The effect of mouth rinsing with a carbohydrate $(\mathrm{CHO})$ solution on exercise performance is inconclusive with no benefits observed in the fed state. This study examined the effect of $\mathrm{CHO}$ mouth rinse or $\mathrm{CHO}$ ingestion on performance in 9 moderately trained male cyclists.

Methods: Four trials were undertaken, separated by 7 days, in a randomized, counterbalanced design. Each trial included a 90-min glycogen-reducing exercise protocol, immediately followed by a low $\mathrm{CHO}$ meal and subsequent overnight fast; the following morning a 1-h cycling time trial was conducted. The trials included $15 \% \mathrm{CHO}$ mouth rinse (CHOR), $7.5 \% \mathrm{CHO}$ ingestion (CHOI), placebo mouth rinse and placebo ingestion. Solutions were provided after every $12.5 \%$ of completed exercise: $1.5 \mathrm{~mL} \cdot \mathrm{kg}^{-1}$ and $0.33 \mathrm{~mL} \cdot \mathrm{kg}^{-1}$ body mass during ingestion and rinse trials, respectively. During rinse trials participants swirled the solution for $8 \mathrm{~s}$ before expectorating. Blood samples were taken at regular intervals before and during exercise.

Results: Performance time was not different between trials $(P=0.21)$ but the $4.5-5.2 \%$ difference between $\mathrm{CHOI}$ and other trials showed moderate practical significance (Cohen's d 0.57-0.65). Power output was higher in CHOI relative to other trials $(P<0.01)$. There were no differences between $\mathrm{CHOR}$ and placebo groups for any performance variables. Plasma glucose, insulin and lactate concentrations were higher in $\mathrm{CHOl}$ relative to other groups $(P<0.05)$.

Conclusions: In a fasted and glycogen-reduced state ingestion of a $\mathrm{CHO}$ solution during high-intensity exercise enhanced performance through stimulation of insulin-mediated glucose uptake. The $\mathrm{CHO}$ mouth rinsing had neither ergogenic effects nor changes in endocrine or metabolic responses relative to placebo.
\end{abstract}

Keywords: Ergogenic aid, Fluid ingestion, Time trial, Sports drink, Mouthwash, Supplementation

\section{Background}

The ergogenic effects of carbohydrate $(\mathrm{CHO})$ ingestion during prolonged exercise are well known. With $\mathrm{CHO}$ ingestion, better maintenance of blood glucose [1], increase in $\mathrm{CHO}$ oxidation [1] and/or sparing of muscle glycogen during intermittent [2] and continuous [3] high-intensity exercise have been shown. However, the work of Carter et al. [4] suggested there may be other mechanisms of action for exogenous $\mathrm{CHO}$ ingestion. Cyclists performed a $40-\mathrm{km}$ time trial where, in one trial, a glucose solution was infused and in the other trial a saline solution was infused [4]. Although the blood glucose

\footnotetext{
* Correspondence: A.Ali@massey.ac.nz

'School of Sport and Exercise, Massey University, Auckland, New Zealand Full list of author information is available at the end of the article
}

concentrations and glucose disappearance were twice as high in the glucose-infused trial, there was no effect on performance. Therefore, the authors suggested there may be other reasons (beyond augmented blood glucose levels) for the ergogenic benefits of $\mathrm{CHO}$ ingestion.

In a subsequent study Carter et al. [5] found that mouth rinsing with a $\mathrm{CHO}$ solution improved performance by $2.9 \%$ during a 1 -h time trial when compared to the placebo solution. Furthermore, $\mathrm{CHO}$ mouth rinsing has been shown to result in higher self-selected running intensities [6] and maximal voluntary contraction [7] without any changes to circulating glucose levels. The mere presence of carbohydrates in the mouth has been postulated to influence endurance performance by 'central factors' as a $\mathrm{CHO}$ mouth rinse may involve 
stimulation of cortical taste neurons [5]; these receptors are thought to link with neuronal communication to pleasure centres in the brain [8]. Evidence to support this hypothesis is lacking, however, there is a suggestion that the brain can sense certain composition changes in the mouth and activation of these taste-related brain regions can influence emotion and behaviour [9]. Therefore, carbohydrate sensing in the mouth may positively impact exercise performance.

It has been reported that $\mathrm{CHO}$ ingestion can cause gastrointestinal (GI) discomfort and lead to decrements in endurance performance [10]. In this case mouth rinsing with a $\mathrm{CHO}$ solution may therefore stimulate ergogenic benefits without subsequent GI distress. However, Whitham and McKinney [11] showed that although a $\mathrm{CHO}$ mouth rinse did not cause GI discomfort in experienced runners, there were no performance benefits either. Other studies also report no improvements in performance from $\mathrm{CHO}$ mouth rinsing [12, 13]. Beelen et al. [12] examined the effects of $\mathrm{CHO}$ mouth rinsing $2 \mathrm{~h}$ after a standardised meal in welltrained cyclists. Because there were no differences in performance, power output or heart rate between placebo and $\mathrm{CHO}$ trials, the authors suggested that the presence of small amounts of $\mathrm{CHO}$ in the mouth does not impact performance when applied in more ecologically valid, postprandial conditions. However, from an evolutionary perspective, the presence of $\mathrm{CHO}$ in the mouth may be more pertinent when glycogen levels are compromised [12]. Nevertheless, Lane et al. [14] showed that, relative to a placebo, mouth rinsing in an unfed state showed better performance (3.4\%) than within a fed condition (1.8\%). Stannard et al. [15] found that exercising on an empty stomach enhances muscle metabolism in trained male cyclists. It is tempting to speculate that $\mathrm{CHO}$ mouth rinsing may therefore enhance exercise intensity (from a centrally mediating perspective) without compromising the benefits of exercising on an empty stomach; therefore allowing for an enhanced training stimulus and promoting more rapid muscular adaptations.

Numerous studies have shown the benefits of fluid ingestion on exercise performance (see Sawka et al. [16] for review). Arnaoutis et al. [17] investigated whether simply rinsing the mouth with water-the drink of choice for many athletes (many of whom simply gargle/rinse with water)-may impact performance. Their results showed that water ingestion enhanced performance in comparison to mouth rinsing, possibly via activation of the oral-pharyngeal receptors. Below et al. [18] have previously shown that fluid and $\mathrm{CHO}$ ingestion have independent and additive effects on endurance performance and a similar study design may therefore help to evaluate the effects of $\mathrm{CHO}$ mouth rinsing.

Therefore, the aim of this study was to investigate whether there are independent and/or additive effects of carbohydrate fluid mouth rinsing, placebo fluid ingestion and carbohydrate fluid ingestion on 1-h time trial cycling performance, when subjects are in a glycogendeprived state.

\section{Methods \\ Participants}

Nine male recreationally trained cyclists and triathletes (age $32.7 \pm 13.0 \mathrm{y}$, stature $1.80 \pm 0.05 \mathrm{~m}$, body mass $(\mathrm{BM}) 72.7 \pm$ $7.3 \mathrm{~kg}$ and peak oxygen uptake ( $\dot{\mathrm{VO}}_{2}$ peak) $55.1 \pm 7.6 \mathrm{~mL}$. $\mathrm{kg}^{-1} \cdot \mathrm{min}^{-1}$; mean $\pm \mathrm{SD}$ ) volunteered to participate in this study. Their training time ranged from 5 to $20 \mathrm{~h}$ per week, interspersed with competitive events. The study was approved by the Massey University Human Ethics Committee, Southern A (approval number 10/01). Following completion of a medical history questionnaire, written informed consent was obtained from all participants.

\section{Preliminary measurements}

Following body mass and stature measurements, participants performed a graded exercise test, on an electronically braked cycle ergometer (model Excalibur, Lode, Groningen, Netherlands), to determine $\dot{\mathrm{V}} \mathrm{O}_{2}$ peak [19]. After a 5-min warm-up at $100 \mathrm{~W}$, workload was increased by $50 \mathrm{~W}$ every $2.5 \mathrm{~min}$ until a heart rate of 160 beat $\cdot \mathrm{min}^{-1}$ was reached. After this point, workload was increased by $25 \mathrm{~W}$ every $2.5 \mathrm{~min}$. Gas samples $(60 \mathrm{~s})$, using Douglas bag method, were collected at every 2.5 min stage. The graded exercise test continued until participants reached volitional exhaustion. The participants were asked to signal when they could go for only one more minute and a final sample was collected. The participants' maximum power output achieved was recorded and they were verbally encouraged throughout the test. The Douglas bag samples were then analysed to determine peak $\mathrm{VO}_{2}$. Participants then underwent a shortened version of the glycogen reduction exercise protocol to familiarise themselves to the relative intensities of exercise [20]. After a brief rest interval (5-10 min) participants performed a full familiarisation of the 1-h cycling time trial protocol [21]. During the performance trial the participants were introduced to the oxygen uptake measures and the mouth rinse protocol. Information on how to perform the two-day dietary record was provided after the cessation of exercise and prior to leaving the laboratory.

\section{Experimental trials}

Participants completed four main trials, within a Latin square design, with each trial separated by seven days. Exercise was completed in an air-conditioned laboratory with no difference between trials for temperature (18.4 $\pm 0.2{ }^{\circ} \mathrm{C}$ to $20.2 \pm 0.2{ }^{\circ} \mathrm{C} ; P=0.14$ ) or humidity ( $46.4 \pm 1.2$ to $48.6 \pm 1.4 \% ; P=0.17$ ). A counterbalanced design, with 
participants completing the trials in different orders, was used to counteract possible order effects. Participants were asked to avoid caffeine and alcohol consumption and to record dietary intake over the 48-h period prior to the first main trial and to replicate their intake prior to the other three trials. Diets were analysed for total energy intake and relative contributions of food types (FoodWorks 5.0, Xyris Software, Australia). During this time mean energy $\left(167 \pm 36 \mathrm{~kJ} \cdot \mathrm{kg}\right.$ body mass ${ }^{-1} \cdot$ day $^{-1}$ to $196 \pm$ $\left.55 \mathrm{~kJ} \cdot \mathrm{kg}^{-1} \cdot \mathrm{day}^{-1} ; P=0.57\right)$ and $\mathrm{CHO}\left(4.9 \pm 1.2 \mathrm{~g} \cdot \mathrm{kg}^{-1}\right.$. day $^{-1}$ to $5.9 \pm 1.6 \mathrm{~g} \cdot \mathrm{kg}^{-1} \cdot$ day $\left.^{-1} ; P=0.35\right)$ intake were not different among trials. Each main trial took place over two days. On the evening of Day 1, following measurement of body mass and a fasting blood sample, participants underwent a glycogen-reducing exercise protocol followed by a low $\mathrm{CHO}$ meal and then a subsequent overnight fast; the following morning a performance time trial ride was conducted.

The glycogen reduction exercise was designed to reduce the glycogen content in both type I and type II muscle fibres [20]. This procedure required the participants to cycle for $30 \mathrm{~min}$ at $70 \%$ peak, followed by three 50 -s 'sprints' at double the resistive load (with 2 min rest between each bout), and then another $45 \mathrm{~min}$ at $70 \%$ peak. Although muscle glycogen was not measured in the current study, this type of exercise has been shown to reduce muscle glycogen stores from $110-170 \mathrm{mmol}$ glycosyl $\mathrm{U} \cdot \mathrm{kg}^{-1}$ wet wt to $13 \mathrm{mmol}$ glycosyl $\mathrm{U} \cdot \mathrm{kg}^{-1}$ [22]. After completing this exercise the participants were provided with a low $\mathrm{CHO}$ meal which was the last meal of the day (energy content of $56 \mathrm{~kJ} \cdot \mathrm{kg}^{-1} \mathrm{BM}$ and $\mathrm{CHO}$ content of $1 \mathrm{~g} \cdot \mathrm{kg}^{-1} \mathrm{BM}$; [23]). Thereafter, they were instructed not to consume any other food following this meal, but were allowed to ingest water ad libitum. Participants arrived in the laboratory the following morning having fasted for $10-12 \mathrm{~h}$.

Figure 1 shows a schematic of the experimental protocol. Upon arrival on the morning of Day 2 participants' nude body mass was determined and a cannula was inserted into an antecubital vein (which was kept patent by frequent flushing with sterile saline). Following a $10-\mathrm{ml}$ fasting blood sample and a brief warm-up (5 min at $40 \%$ Wmax), participants underwent the 1-h time trial [21]. Briefly, participants performed a predetermined amount of work as fast as possible based on the following formula:

Total work $(\mathrm{J})=0.75 \cdot \mathrm{Wmax} \cdot 3600 \mathrm{~s}$

The total amount of work (J) to be performed was calculated by assuming that the participants could cycle at $75 \%$ of their maximum power output (Wmax) for $60 \mathrm{~min}$ [21]. Power output during the performance trial was self-selected. Participants received no verbal encouragement and no information of performance other than the amount of work completed.

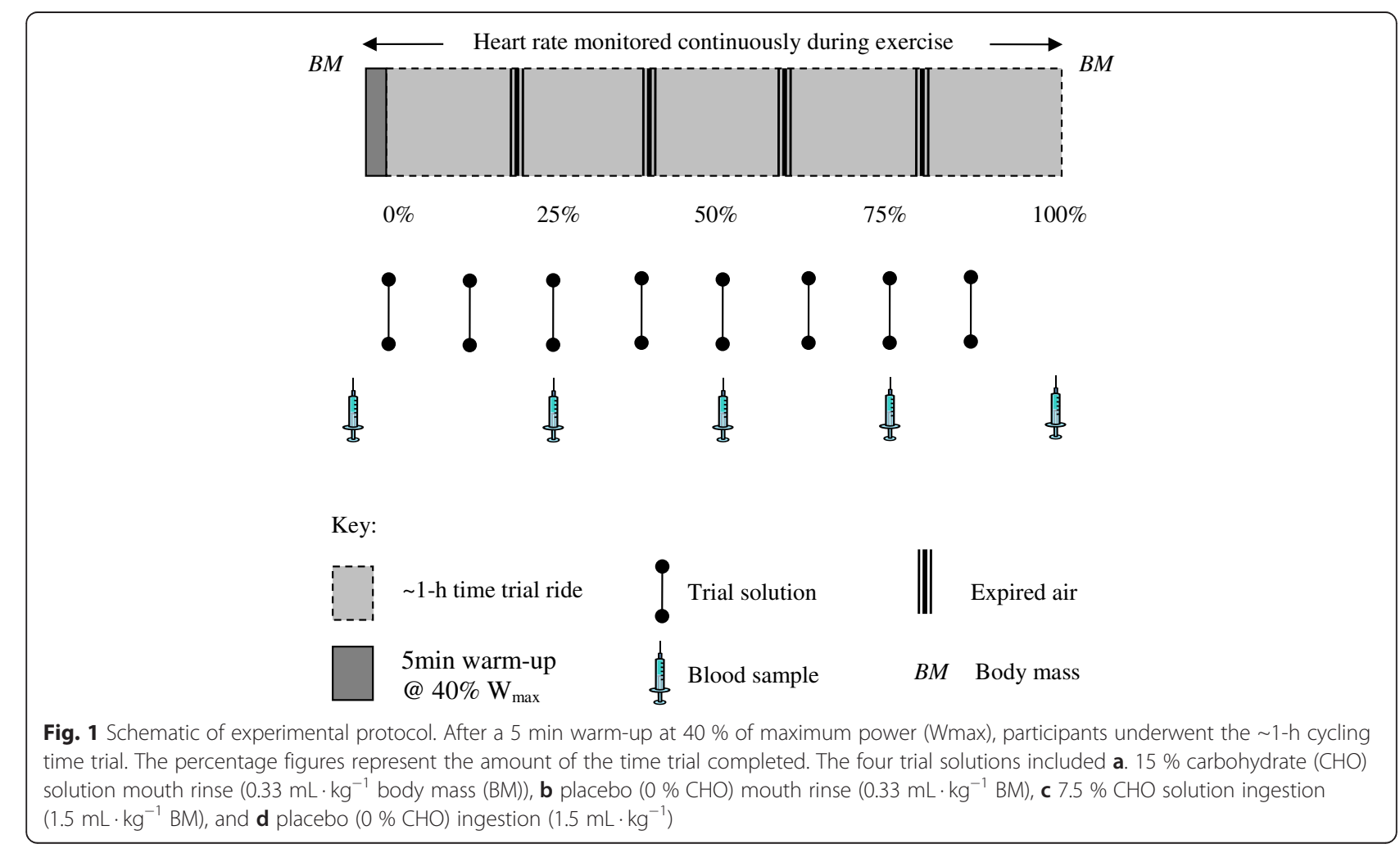




\section{Trial solutions}

Four trial solutions were used in this study. In Trial A, a $15 \% \mathrm{CHO}$ solution was used for rinsing and in Trial $\mathrm{C}$ a $7.5 \% \mathrm{CHO}$ solution was used for ingestion. The $15 \% \mathrm{CHO}$ mouth rinse solution $\left(118 \mathrm{~g} \cdot \mathrm{L}^{-1}\right.$ sucrose and $32 \mathrm{~g} \cdot \mathrm{L}^{-1}$ maltodextrin) and $7.5 \% \mathrm{CHO}$ solution (59 $\mathrm{g} \cdot \mathrm{L}^{-1}$ sucrose and $16 \mathrm{~g} \cdot \mathrm{L}^{-1}$ maltodextrin) were made up according to methods used previously [24]. The higher energy content for the mouth rinse solution was chosen as functional magnetic resonance imaging (fMRI) studies have used similar concentrations and shown changes in brain function and improvements in motor output [25]. The placebo solutions (Trials B and D) were taste and colour matched (confirmed using triangulation testing) and contained $0 \% \mathrm{CHO}$ and artificial sweeteners. The solutions had a mandarin flavour and were made onsite at the Massey University Albany Food Technology Laboratory and were stored in a refrigerator (Fisher and Paykell, c450, New Zealand).

During the ingestion trials $1.5 \mathrm{~mL} \cdot \mathrm{kg}^{-1}$ body mass solutions were consumed using a sipper bottle. The participants were informed to finish the solution when it was given to them. The trial solutions were given immediately before exercise and after every $12.5 \%$ of exercise completed ( 8 times in total) thus $872 \pm 88 \mathrm{~mL}$ was consumed by participants. In the $\mathrm{CHOI}$ trial participants consumed $65.4 \pm 6.6 \mathrm{~g}$ of $\mathrm{CHO}$. During the mouth rinsing trials, the participants were required to rinse $0.33 \mathrm{~mL} \cdot \mathrm{kg}^{-1}$ body mass solutions and fluids were given to the participant in a plastic volumetric syringe (Omnifix 50/60 ml Luer; Germany). Participants self-administered the mouth rinse and were asked to swirl the solution in their mouth for $8 \mathrm{~s}$. After rinsing, participants expectorated all of the solution into a pre-weighed container which was then measured using electronic scales accurate to $0.0001 \mathrm{~g}$ (Sartorius LE3235, Germany). The expectorate volume was checked to ensure it was the same volume as what was initially provided before disposal. The mouth rinse was also administered after every $12.5 \%$ of exercise was completed (8 times in total).

\section{Physiological measures}

Heart rate $(\mathrm{HR})$ was measured continuously during time trials using short range telemetry (Polar Electro S6101, Kempele, Finland). HR data were downloaded upon completion of the performance trial (Polar Precision Performance software version 3, Kempele, Finland). Expired air samples, using the Douglas bag technique, were taken after 20, 40, 60 and $80 \%$ of exercise completed (1-min sample was taken after mouth piece had been inserted for $30 \mathrm{~s}$ to clear dead space). $\mathrm{CO}_{2}$ and $\mathrm{O}_{2}$ were determined using an analyser (Servomex 1440 Gas Analyser, Crowborough, England) prior to determination of gas volumes (Harvard Apparatus, Edenbridge, England). Using indirect calorimetry calculations, energy expenditure and fat and $\mathrm{CHO}$ oxidation rates during exercise were estimated.

\section{Blood dispensing and analyses}

Ten millilitres of blood were collected prior to the glycogen reducing exercise, prior to and after every $25 \%$ of exercise completed during the 1-h time trial. Six millilitres of the sample were collected in an EDTA tube and $4 \mathrm{ml}$ were collected in a heparinised tube. To determine the haematocrit, three microhematocrit tubes were filled with heparinised blood and were then centrifuged at $10,000 \mathrm{rev} \cdot \mathrm{min}^{-1}$ for 5 min (Haematocrit 210, Hettich, Germany). Haematocrit was measured using a microhematocrit reader (Hawkesley, Cambridge, England) and haemoglobin was determined using an automated method (Hemocue, AB, Angelholm, Sweden). The vacutainer tubes were centrifuged at $1500 \mathrm{~g}$ (Hanil, MF50, Korea) for $10 \mathrm{~min}$ at $4{ }^{\circ} \mathrm{C}$ and stored in cryotubes at $-80{ }^{\circ} \mathrm{C}$ (Thermaforma 929, Nunc, Ohio, USA) for later analysis of metabolites and hormones.

Lactate was analysed via an enzymatic method using lactate oxidase (Roche Diagnostics $\mathrm{GmbH}$. Switzerland; Flexor E, Vitalab Netherlands). Plasma glucose was determined using a hexokinase method (Roche Diagnostics, Basel, Switzerland; Flexor E, Vital Scientific NV, 6956 AV Spankeren/Dieren, The Netherlands). Free fatty acids (FFA) were assayed by an ACS-ACOD enzymatic method and FFA concentrations were then obtained by colorimetry (Wako Pure Chemical Industries, Ltd. Osaka, Japan and Flexor E, Vitalab Scientific NV, 6956 AV Spankeren/Dieren, The Netherlands). Insulin and C-peptide were analysed using Mercodia ultrasensitive insulin and C-peptide ELISA (a solid phase two-site enzyme immunoassay) kits, respectively. The samples were analysed in duplicate and the optical density was read at $450 \mathrm{~nm}$ on a plate reader (2030 Victor X, Perkin Elmer, Finland).

\section{Statistical analysis}

The performance data were examined using mixedmodel analysis of variance (ANOVA) with subjects as random effects and time and treatment as fixed effects. Data collected for most of the other variables were compared using a two-way ANOVA with repeated measures (SPSS version 18.0, Chicago, IL) to examine main effects of i) treatment (PLAR, PLAI, CHOR, CHOI) and ii) time (percentage of exercise completed) and iii) interaction of treatment $\mathrm{x}$ time. Mauchly's test for sphericity was applied to the data. When sphericity was violated the Huynh-Feldt estimate was used to correct the data. One-way ANOVA was also used to examine mean data between trials (e.g. dietary composition, ambient temperature). When significant differences between the interventions were identified by ANOVA, post-hoc Student's $t$-test, using the Holm-Bonferroni adjustment, were performed. Data are presented as means $\pm \mathrm{SD}$ 
(unless otherwise indicated). Statistical significance was set at $P<0.05$, whereas a 'trend' was $P<0.09$. Practical significance was reported using effect sizes calculated from Cohen's d. A large effect size was determined as 0.8 , medium as 0.5 and small as 0.2 [26].

\section{Results}

\section{Performance}

There was no statistical difference in performance time between trials $(P=0.21$; Fig. 2a). However, in terms of practical significance, CHOI $(3920 \pm 288 \mathrm{~s})$ was $4.5-5.2 \%$ faster than other trials (4096-4124 s; Cohen's d 0.57-0.65). Power output decreased throughout the time trial for all conditions (main effect of time, $P<0.01$; Fig. 2b). Power output was higher in CHOI $(231 \pm 33$ Watts) relative to other trials (221-223 Watts; main effect of treatment $P<0.01$; Cohen's d $0.21-0.31)$. There was no interaction of treatment $\mathrm{x}$ time $(P=0.41)$.

\section{Physiological and metabolic responses}

There were no differences in body mass or plasma volume between the pre-glycogen reduction exercise (evening Day 1) and pre-time trial period (morning of Day 2) between trials or over time. Body mass loss was higher

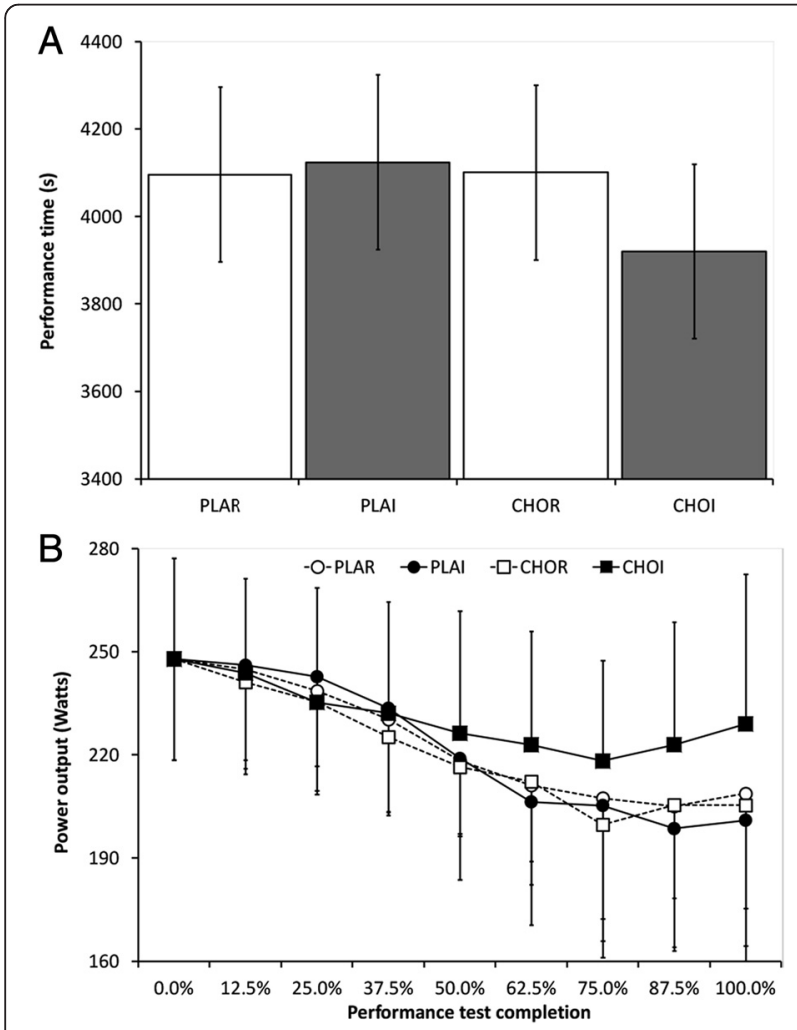

Fig. 2 Mean ( \pm SD) performance characteristics during 1-h cycling time trial: a Performance time (s) and $\mathbf{b}$ Power output (Watts). PLAR = placebo mouth rinse; $\mathrm{PLAl}=$ placebo ingestion; $\mathrm{CHOR}=$ carbohydrate mouth rinse; $\mathrm{CHOI}=$ carbohydrate ingestion in the two rinsing trials $(1.9 \pm 0.6 \%$ PLAR; $1.7 \pm 0.4 \%$ CHOR) relative to the ingestion trials $(0.6 \pm 0.3 \%$ PLAI; $0.6 \pm 0.5 \% \mathrm{CHOI} ; P<0.01)$. There were no differences between trials or over time for decrease in plasma volume as a percentage of total blood volume from pre to post-exercise. HR increased with duration of exercise (main effect of time, $P<0.01$ ), but was not different between trials $\left(P=0.79\right.$; Fig. 3a). Oxygen uptake $\left(\% \mathrm{~V}_{2}\right.$ peak) decreased throughout exercise $(P=0.02)$, but was not different between trials $\left(P=0.27\right.$; Fig. 3b). Percent $\dot{\mathrm{V}}_{2}$ peak also decreased over time $(P=0.01)$, but was not different between trials $(P=0.60$; Fig. 3c).

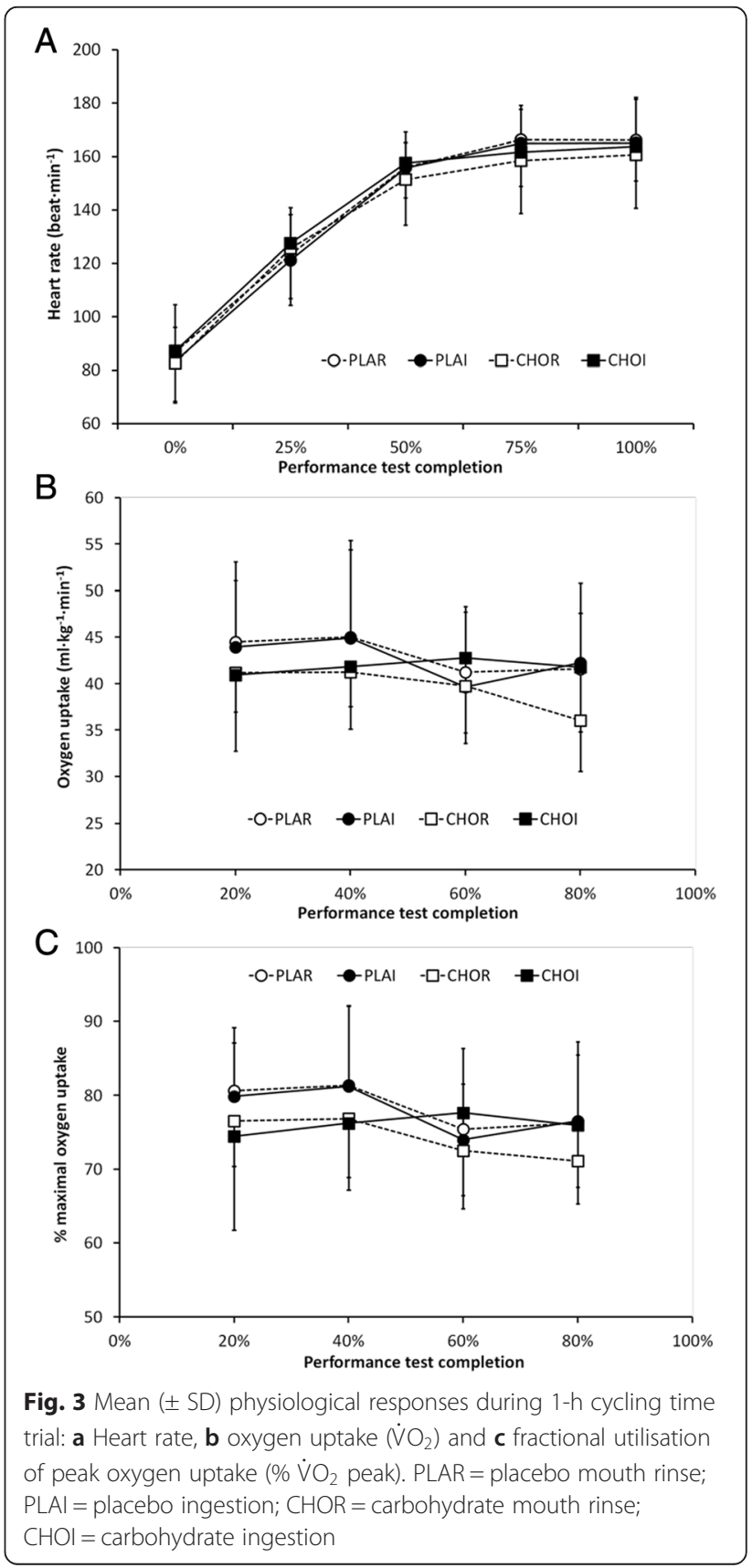


Respiratory exchange ratio (RER) was unchanged over time $(P=0.10)$ but showed a trend to be higher in $\mathrm{CHOI}$ $(0.88 \pm 0.08)$ relative to other trials $(0.81-0.84 ; P=0.06$; Fig. 4a). Estimated energy expenditure rates showed a trend to decrease throughout exercise $(P=0.07)$, but were not different between trials $(P=0.10$; Fig. $4 \mathrm{~b})$. Estimated $\mathrm{CHO}$ oxidation rates showed no effects of time $(P=0.64)$ or treatment $(P=0.14)$. However, there was an interaction of treatment $\times$ time $(P=0.049)$ with post-hoc analysis showing higher estimated $\mathrm{CHO}$ oxidation rates in $\mathrm{CHOI}$ relative to other trials at $80 \%$ of completed exercise $\left(34 \pm 12 \mathrm{~kJ} \cdot \mathrm{min}^{-1}\right.$ vs. $18-23 \mathrm{~kJ} \cdot \mathrm{min}^{-1} ; P<0.05$; Fig. $\left.4 \mathrm{c}\right)$. There were no time $(P=0.90)$, treatment $(P=0.12)$ or interaction $(P=0.19)$ effects for estimated fat oxidation rates (Fig. 4d).

Mean plasma glucose was higher in CHOI (5.3 \pm $0.9 \mathrm{mM})$ relative to other trials $(4.4-4.8 \mathrm{mM} ; P<0.01)$. Furthermore, there was an interaction of treatment $x$ time $(P<0.01)$ with higher plasma glucose concentrations in $\mathrm{CHOI}$ at $75 \%(5.5 \pm 0.7 \mathrm{mM})$ and $100 \%(6.0 \pm 1.2 \mathrm{mM})$ of completed exercise relative to other trials $(4.1-4.8 \mathrm{mM} ; P<$ 0.05; Fig. 5a). Plasma FFA increased over time $(P<0.01)$, with no differences between trials $(P=0.40)$ or interaction of treatment $\mathrm{x}$ time $(P=0.09$; Fig. $5 \mathrm{~b})$. Plasma insulin concentrations decreased over time $(P<0.01)$ and were higher in the CHOI group $\left(2.3 \pm 1.4 \mathrm{mU} \cdot \mathrm{L}^{-1}\right)$ relative to other trials $\left(1.1-1.6 \mathrm{mU} \cdot \mathrm{L}^{-1} ; P<0.01\right)$. Furthermore, there was an interaction of treatment $\mathrm{x}$ time $(P=0.01)$ with post-hoc analysis showing higher plasma insulin values in the $\mathrm{CHOI}$ group relative to other trials after 50,75 and $100 \%$ of completed exercise $(P<0.05$; Fig. 5 c). Plasma $C$-peptide decreased over time $(P=0.02)$, but was not different between trials $(P=0.10)$. However, $C$-peptide remained stable in the $\mathrm{CHOI}$ group, but decreased in all other trials (interaction of treatment $\mathrm{x}$ time, $P=0.02$; Fig. $5 \mathrm{~d}$ ). Plasma lactate increased over time $(P<0.01)$ and was different between trials $(P=0.01)$, with post-hoc analysis showing higher values in $\mathrm{CHOI}(3.0 \pm 2.0 \mathrm{mM})$ relative to $\mathrm{CHOR}$ $(2.0 \pm 1.4 \mathrm{mM} ; P<0.05$; Fig. $5 \mathrm{e})$ only; there was no interaction of treatment $\mathrm{x}$ time $(P=0.17)$.

\section{Discussion}

This study investigated the effects of $\mathrm{CHO}$ mouth rinse, $\mathrm{CHO}$ fluid ingestion, placebo mouth rinse and placebo
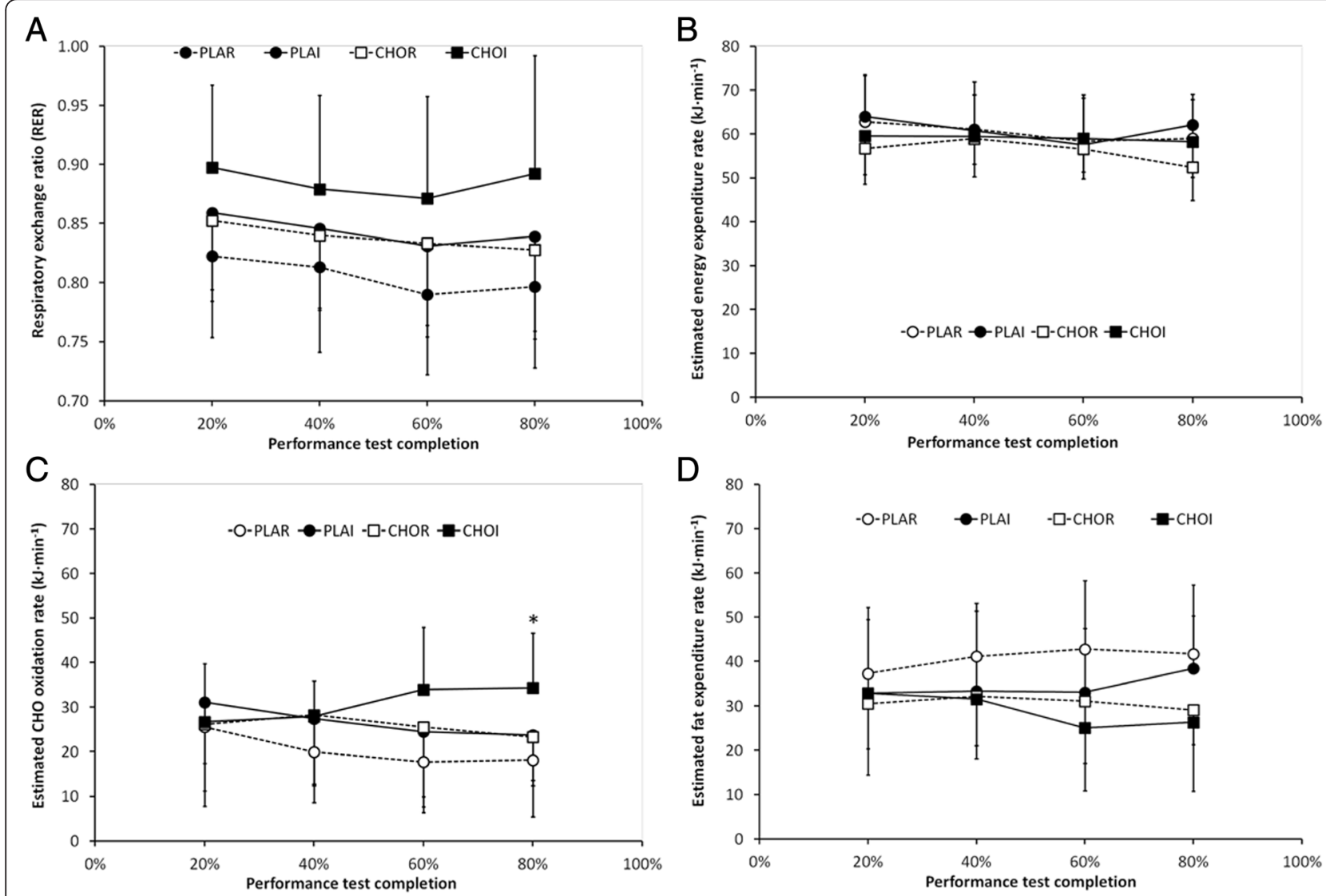

Fig. 4 Mean ( \pm SD) indirect calorimetry measures during 1-h cycling time trial: a respiratory exchange ratio (RER), b estimated energy expenditure rate, $\mathbf{c}$ estimated carbohydrate $(\mathrm{CHO})$ oxidation rate and $\mathbf{d}$ estimated fat oxidation rate. PLAR = placebo mouth rinse; PLAl = placebo ingestion; $\mathrm{CHOR}=$ carbohydrate mouth rinse; $\mathrm{CHOI}=$ carbohydrate ingestion. ${ }^{*}$ signifies higher values for $\mathrm{CHOl}$ relative to other trials $(P<0.05)$ 


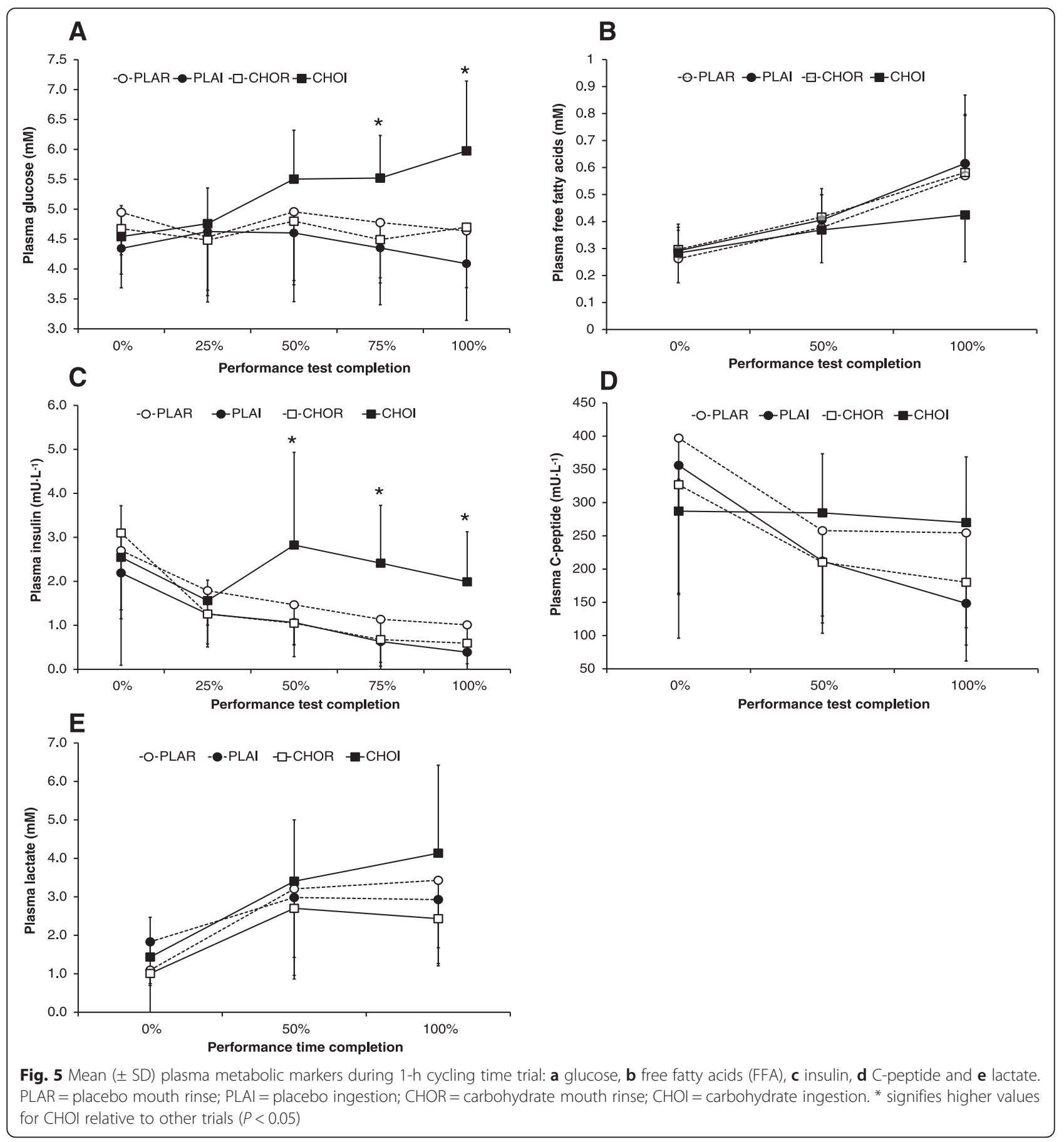

fluid ingestion on cycling performance and metabolic and endocrine responses in subjects with low initial glycogen levels. There was no performance or metabolic stimulation with the $\mathrm{CHO}$ or placebo mouth rinse solutions. However, ingestion of $\mathrm{CHO}$, in comparison with fluid ingestion and mouth rinse trials, increased power output during the performance test. Ingesting the $\mathrm{CHO}$ solution increased circulating plasma glucose, lactate and insulin concentrations, and increased estimated
$\mathrm{CHO}$ oxidation - especially towards the latter stages of the time trial.

Mouth rinsing with $\mathrm{CHO}$ solutions has been promoted as a way of inducing ergogenic benefits for endurance athletes [5, 6]. However, in previous studies, under fed conditions, $\mathrm{CHO}$ mouth rinsing did not show any performance improvements [12], therefore indicating that the body may need to be in a glycogen-compromised state to realise any potential ergogenic benefit. The 
results of our study show that, even within low glycogen conditions, ingestion of a $\mathrm{CHO}$ solution leads to better power output and enhanced metabolic responses in comparison with simply rinsing the mouth with a $\mathrm{CHO}$ solution. Our results are in contrast to the findings of Lane et al. [14] who showed that $\mathrm{CHO}$ mouth rinsing provides performance benefits to well-trained athletes under fed or unfed conditions.

Methodological differences may help to explain some of the discrepancies between studies. Previous research that showed ergogenic benefits used $\mathrm{CHO}$ vs. placebo mouth rinse trials $[5,6,14,27]$ or $\mathrm{CHO}$ mouth rinse vs. $\mathrm{CHO}$ ingestion trials [28]. Our study is the first to use a comparison between fluid rinse, fluid ingestion, $\mathrm{CHO}$ mouth rinse and $\mathrm{CHO}$ ingestion trials within the same experiment (Latin square design). Participants' cardiorespiratory fitness, as indicated by $\dot{\mathrm{V}}_{2}$ max values, was higher in the aforementioned studies $\left(61-64 \mathrm{~mL} \cdot \mathrm{kg}^{-1} \cdot \mathrm{min}^{-1}\right)$ whereas in the current study the mean value was $55 \mathrm{~mL} \cdot \mathrm{kg}^{-1} \cdot \mathrm{min}^{-1}$. However, based on percent $\dot{\mathrm{VO}}_{2}$ peak, HR and lactate values, our participants were working at similar relative physiological loads. Small differences in $\mathrm{CHO}$ concentrations (6-7.5 \%), CHO type (maltodextrin, sucrose and/or glucose) and rinsing durations ( $\sim 5 \mathrm{~s}$ ) are unlikely to explain the discrepancies between the different studies. Indeed, we incorporated a higher (15\%) CHO rinse solution and utilised an 8-s rinse protocol to maximise any potential benefit of a $\mathrm{CHO}$ mouth rinse. Therefore, we believe metabolic reasons may provide more plausible answers for the lack of benefit from $\mathrm{CHO}$ mouth rinsing.

Gant et al. [7] found that both $\mathrm{CHO}$ ingestion and mouth rinsing immediately facilitate corticomotor output prior to the peripheral availability of glucose. There were immediate ergogenic effects observed in maximal voluntary force and motor evoked potentials with the presence of $\mathrm{CHO}$ in the mouth, but no changes to circulating glucose levels. Following $\mathrm{CHO}$ ingestion there was peripheral appearance of blood glucose and an increase in force, however this had no effect on the primary motor cortex. It was suggested that the increase in force production observed with an increase in plasma glucose concentration after $\mathrm{CHO}$ ingestion was related to peripheral rather than central factors; the results of the current study certainly support this argument.

$\mathrm{CHO}$ ingestion has previously been shown to maintain blood glucose concentrations and $\mathrm{CHO}$ oxidation rates and lead to significant improvements in exercise capacity $[1,29]$. In our subjects, plasma glucose levels were elevated with $\mathrm{CHO}$ ingestion (Fig. 5a) and power output was maintained in the $\mathrm{CHOI}$ group for the duration of the study (Fig. 2b). Furthermore, although estimated energy expenditure rates were unchanged between groups (Fig. 4b), the higher $\mathrm{CHO}$ oxidation rate (Fig. 4c) likely maintained power output in the $\mathrm{CHOI}$ group. As the subjects had low endogenous stores of glycogen prior to the performance time trial, it appears the exogenous $\mathrm{CHO}$ provision provided an impetus for higher $\mathrm{CHO}$ oxidation rates. Tsintzas et al. [3] suggested that when insulin and blood glucose levels were elevated muscle glycogen sparing occurred. Therefore, elevated plasma insulin (Fig. 5c) and glucose concentrations (Fig. 5a) during the $\mathrm{CHOI}$ trial suggests our subjects may have undergone some muscle glycogen sparing. However, without undertaking muscle biopsy, MRI and/or tracer studies assertions relating to exogenous $\mathrm{CHO}$ oxidation and/or glycogen sparing cannot be confirmed. Nevertheless, it appears that although $\mathrm{CHO}$ mouth rinsing may trigger central nervous system responses, our findings suggest that without actual ingestion of $\mathrm{CHO}$, power output or metabolic changes do not take place. Therefore, contrary to previous suggestions by Beelen et al. [12], our study suggests that $\mathrm{CHO}$ mouth rinsing does not affect performance in an unfed state.

Insulin and C-peptide were higher in the CHOI group in comparison with the other trials (Fig. $5 \mathrm{c}$ and d). Insulin is the principle hormone responsible for the control of glucose metabolism and C-peptide is a strong measure of insulin secretion [30]. The C-peptide levels, reflecting insulin secretion, decreased over time during high performance exercise in all groups that did not ingest $\mathrm{CHO}$. Interestingly, $\mathrm{CHO}$ ingestion seems to ameliorate this decline in $\mathrm{C}$ peptide levels, which would contribute to the elevated insulin concentration observed in the $\mathrm{CHOI}$ group. The changes in insulin may help to explain the increase in power output in the $\mathrm{CHOI}$ group relative to the $\mathrm{CHOR}$ trials. It is tempting to speculate that the increase in power output could very well be driven by changes in insulin sensitivity and increased fuel utilisation. These results, together with the increase in plasma glucose levels in the CHOI group, may suggest that an increase in insulin action may drive, at least in part, the increase in performance observed in this study. The exact role of changes in insulin secretion, sensitivity or action with $\mathrm{CHO}$ ingestion during highintensity exercise deserves further investigation including studies involving dynamic insulin sensitivity tests [30]. Other blood plasma parameters that may reflect changes in insulin action (e.g. leptin, glucagon-like peptide-1 or ghrelin) could also be investigated in future studies that expand inquiries into changes of metabolic regulation in this setting.

Losses of $2 \%$ body mass during exercise have been reported to decrease endurance performance [31]. In the current study, body mass loss was greater (1.7-1.9\%) in the two mouth rinse trials compared to the two ingestion trials $(0.6 \% ; P<0.01)$. Dehydration has been suggested to increase glycogenolysis [32] and impact on cardiovascular function resulting in an increase in physical strain [33]. Thus, performance may have been expected to be better in 
the PLAI and CHOI groups relative to the mouth rinse groups. However, there was no performance, metabolic or physiological differences in the PLAI group relative to the mouth rinse groups thus suggesting that relative fluid loss and/or dehydration was not the underlying cause of fatigue in the present study. Moreover, contrary to the findings of Arnaoutis et al. [17], who used already dehydrated participants, there was no difference in performance between fluid rinse vs. fluid ingestion trials. Therefore, we speculate that the changes in power output were not simply a result of hydration status but related to the $\mathrm{CHO}$ ingested during high-intensity exercise.

One could argue that participants were in a fasted state which may not be realistic in a practical setting [34]. However, we believe that the present findings are an accurate representation of endurance performance as it is not uncommon for athletes who have early morning events to begin exercise in a fasted state, for example Ironman competitors [13]. Furthermore, although GI discomfort was not formally assessed in the present study, when participants were asked if they had experienced GI discomfort in the present trials there were no issues reported. Anecdotal comments suggest that many of the participants felt thirsty and dehydrated during the rinsing trials and thus preferred the ingestion trials. They reported that they were tempted to swallow the solution because of the increase in thirst that they had experienced. Subjects also found it difficult to hold their breath while they swirled the solution around in their mouth and found it hard to maintain their cadence for the $8 \mathrm{~s}$ during the mouth rinse process. Issues relating to social acceptability (i.e. spitting) may also deter athletes from pursuing such a method. Due to the issues of hygiene and the practical aspects, further analysis is needed to examine if sports performance mouth rinsing is possible in a 'real life' sporting situation. We believe that unless an athlete experiences GI distress, there seems to be no reason why one may not be able swallow the beverage.

\section{Conclusions}

In summary, in a fasted and glycogen-reduced state, mouth rinsing with a $\mathrm{CHO}$ solution did not show any performance enhancements relative to a placebo control. CHO ingestion, on the other hand, enabled participants to increase power output during exercise; Cohen's d showed moderate effect size performance differences between $\mathrm{CHO}$ ingestion and other trials. Plasma insulin and glucose concentrations were higher in $\mathrm{CHO}$ ingestion trial suggesting possible glycogen sparing. Estimated $\mathrm{CHO}$ oxidation rates were also higher in this trial relative to placebo control and $\mathrm{CHO}$ mouth rinse trials. Our data suggests that under these conditions $\mathrm{CHO}$ mouth rinsing was inferior to $\mathrm{CHO}$ ingestion for moderately trained male cyclists.

\section{Competing interests}

The present manuscript represents original material that has not been submitted for publication elsewhere. There are no conflicts of interest for any of the authors.

\section{Authors' contributions}

CM, MJYY and AA carried out the data collection. MJYY manufactured the test solutions. $\mathrm{CM}$ and $\mathrm{AA}$ performed the statistical analysis. AA and $\mathrm{BHB}$ conceived the study, and participated in its design and coordination and helped to draft the manuscript. All authors read and approved the final manuscript.

\section{Acknowledgements}

The authors would like to thank Simone Ackermann, Sarah Jansen, Wendy Jessup and Laura Kingsley-Smith for help with data collection, Simon Bennett for technical support, Leiyan Wang for statistical analysis assistance and the participants for providing their time and effort to complete this study.

\section{Author details}

${ }^{1}$ School of Sport and Exercise, Massey University, Auckland, New Zealand. ${ }^{2}$ School of Applied Sciences, Auckland University of Technology, Auckland, New Zealand. ${ }^{3}$ School of Food and Nutrition, Massey University, Auckland, New Zealand.

Received: 7 September 2015 Accepted: 18 April 2016

Published online: 23 April 2016

\section{References}

1. Coyle EF, Coggan AR, Hemmert MK, Ivy JL. Muscle glycogen utilization during prolonged strenuous exercise when fed carbohydrate. J Appl Physiol. 1986;61:165-72.

2. Nicholas CW, Tsintzas K, Boobis L, Williams C. Carbohydrate-electrolyte ingestion during intermittent high-intensity running. Med Sci Sports Exerc. 1999:31:1280-6.

3. Tsintzas K, Williams C, Boobis L, Greenhaff P. Carbohydrate ingestion and glycogen utilisation in different muscle fibres in man. J Physiol. 1995;489:243-50.

4. Carter JM, Jeukendrup AE, Mann $\mathrm{CH}$, Jones DA. The effect of glucose infusion on glucose kinetics during a 1-h time trial. Med Sci Sports Exerc. 2004;36:1543-50.

5. Carter JM, Jeukendrup AE, Jones DA. The effect of carbohydrate mouth rinse on 1-h cycle time trial performance. Med Sci Sports Exerc. 2004;36:2107-11.

6. Rollo I, Williams C, Gant N, Nute M. The influence of carbohydrate mouth rinse on self-selected speeds during a 30-min treadmill run. Int J Sport Nutr Exerc Metab. 2008;18:585-600.

7. Gant N, Stinear CM, Byblow WD. Carbohydrate in the mouth immediately facilitates motor output. Brain Res. 2010;1350:151-8.

8. Chambers ES, Bridge MW, Jones DA. Carbohydrate sensing in the human mouth: effects on exercise performance and brain activity. J Physiol. 2009; 587:1779-94.

9. Kringelbach ML, De Araujo IET, Rolls ET. Taste-related activity in the human dorsolateral prefrontal cortex. Neuroimage. 2004;21:781-8.

10. Van Nieuwenhoven MA, Brouns F, Kovacs EMR. The effect of two sports drinks and water on $\mathrm{Gl}$ complaints and performance during an 18-km run. Int J Sports Med. 2005;26:281-5.

11. Whitham M, McKinney J. Effect of a carbohydrate mouthwash on running time-trial performance. J Sports Sci. 2007;25:1385-92.

12. Beelen M, Berghuis J, Bonaparte B, Ballak SB, Jeukendrup A, Van Loon LJC. Carbohydrate mouth rinsing in the fed state: lack of enhancement of time trial performance. Int J Sport Nutr Exerc Metab. 2009;19:400-9.

13. Rollo I, Williams C, Nevill M. Influence of ingesting versus mouth rinsing a carbohydrate solution during a 1-h run. Med Sci Sports Exerc. 2011;43:468-75.

14. Lane SC, Bird SR, Burke LM, Hawley JA. Effect of a carbohydrate mouth rinse on simulated cycling time-trial performance commenced in a fed or fasted state. Appl Physiol Nutr Metab. 2013;38:134-9.

15. Stannard SR, Buckley AJ, Edge JA, Thompson MW. Adaptations to skeletal muscle with endurance exercise training in the acutely fed versus overnight-fasted state. J Sci Med Sport. 2010;13:465-9.

16. Sawka MN, Burke LM, Eichner ER, Maughan RJ, Montain SJ, Stachenfeld NS. Exercise and fluid replacement. Med Sci Sports Exerc. 2007:39:377-90.

17. Arnaoutis G, Kavouras SA, Christaki I, Sidossis LS. Water Ingestion Improves Performance Compared with Mouth Rinse in Dehydrated Subjects. Med Sci Sports Exerc. 2012;44:175-9. 
18. Below PR, Mora-Rodríguez R, Gonzáles Alonso J, Coyle EF. Fluid and carbohydrate ingestion independently improve performance during $1 \mathrm{~h}$ of intense exercise. Med Sci Sports Exerc. 1995;27:200-10.

19. Kuipers H, Verstappen FTJ, Keizer HA, Geurten P, Van Kranenburg G. Variability of aerobic performance in the laboratory and its physiologic correlates. Int J Sports Med. 1985;6:197-201.

20. Vollestad NK, Tabata I, Medbo Jl. Glycogen breakdown in different human muscle-fiber types during exhaustive exercise of short duration. Acta Physiol Scand. 1992;144:135-41.

21. Jeukendrup AE, Saris WH, Brouns MF, Kester ADM. A new validated endurance performance test. Med Sci Sports Exerc. 1996;28:266-70.

22. Bowtell JL, Gelly K, Jackman ML, Patel A, Simeoni M, Rennie MJ. Effect of oral glutamine on whole body carbohydrate storage during recovery from exhaustive exercise. J Appl Physiol. 1999;86:1770-7.

23. Ali A, Williams C, Nicholas CW, Foskett A. The influence of carbohydrateelectrolyte ingestion on soccer skill performance. Med Sci Sports Exerc. 2007:39:1969-76.

24. Ali A, Duizer L, Foster K, Grigor J, Wei W. Changes in perception of sports drinks when consumed pre, during and post exercise. Physiol Behav. 2011;102:437-43.

25. Turner CE, Byblow WD, Stinear CM, Gant N. Carbohydrate in the mouth enhances activation of brain circuitry involved in motor performance and sensory perception. Appetite. 2014;80:212-9.

26. Cohen J. Statistical Power Analysis for the Behavioural Sciences (2nd ed). Hillsdale (NJ): Lawrence Erlbaum Associates; 1988. p. 273-88.

27. Rollo I, Cole M, Miller R, Williams C. Influence of mouth rinsing a carbohydrate solution on 1-h running performance. Med Sci Sports Exerc. 2010;42:798-804.

28. Pottier A, Bouckaert J, Gilis W, Roels T, Derave W. Mouth rinse but not ingestion of carbohydrate solution improves 1 -h cycle time trial performance. Scand J Med Sci Sports. 2010;20:105-11.

29. Coggan AR, Coyle EF. Carbohydrate ingestion during prolonged exercise: effects on metabolism and performance. Exerc Sport Sci Rev. 1991;19:1-40

30. Wallace TM, Levy JC, Matthews DR. Use and abuse of HOMA modelling. Diabetes Care. 2004;27:1487-95.

31. Saltin B, Costill DL. Fluid and electrolyte balance during prolonged exercise. In: Horton ES, Teejung RL, editors. Exercise, Nutrition and Metabolism. New York: Macmillan; 1988. p. 150-8

32. Hargreaves $M$, Dillo $P$, Angus $D$, Febbraio M. Effect of fluid ingestion on muscle metabolism during prolonged exercise. J Appl Physiol. 1996:80:363-6.

33. Hamilton MT, Gonzalez-Alonso J, Montain SJ. Fluid replacement and glucose infusion during exercise prevent cardiovascular drift. J Appl Physiol. 1991;71:871-7.

34. Heneghan C, Perera R, Nunan D, Mahtani K, Gill P. Forty years of sports performance research and little insight gained. Br Med J. 2012;345:e4797. doi:10.1136/bmj.e4797

\section{Submit your next manuscript to BioMed Central and we will help you at every step:}

- We accept pre-submission inquiries

- Our selector tool helps you to find the most relevant journal

- We provide round the clock customer support

- Convenient online submission

- Thorough peer review

- Inclusion in PubMed and all major indexing services

- Maximum visibility for your research

Submit your manuscript at www.biomedcentral.com/submit

) Biomed Central 